\title{
Managing inflammatory bowel disease in pregnancy: current perspectives
}

This article was published in the following Dove Press journal:

Clinical and Experimental Gastroenterology

14 October 2016

Number of times this article has been viewed

\author{
Matthew Pinder' \\ Katie Lummis' \\ Christian P Selinger ${ }^{1,2}$ \\ 'Leeds Gastroenterology Institute, \\ Leeds Teaching Hospitals NHS Trust, \\ ${ }^{2}$ University of Leeds, Leeds, UK
}

\begin{abstract}
Inflammatory bowel disease (IBD) affects many women of childbearing age. The course of IBD is closely related to pregnancy outcomes with poorly controlled IBD increasing the risk of prematurity, low weight for gestation, and fetal loss. As such, women with IBD face complex decision making weighing the risks of active disease versus those of medical treatments. This review summarizes the current evidence regarding the safety and efficacy of IBD treatments during pregnancy and lactation aiming to provide up-to-date guidance for clinicians. Over $50 \%$ of women have poor IBD- and pregnancy-related knowledge, which is associated with views contrary to medical evidence and voluntary childlessness. This review highlights the effects of poor patient knowledge and critically evaluates interventions for improving patient knowledge and outcomes.
\end{abstract}

Keywords: pregnancy, breast feeding, nursing, inflammatory bowel disease, Crohn's disease, ulcerative colitis

\section{Introduction}

Crohn's disease (CD) and ulcerative colitis (UC) have a high prevalence in young adults. ${ }^{1}$ As such, they often present in women of childbearing age. Given that inflammatory bowel disease (IBD) can significantly affect quality of life, many women have concerns about the effects of pregnancy on their disease control and, in turn, how their disease may affect their fertility, ability to carry a pregnancy to term, and subsequent effects on their children. ${ }^{2,3}$

However, with appropriate therapy and close medical supervision, most women can have a normal pregnancy and deliver a healthy baby. While women with IBD should obviously follow general medical advice given to all women contemplating conception, there are specific issues pertaining to pregnancy in IBD, from preconception through the pregnancy itself and continuing into the postpartum period.

As such, women and their physicians can face some complex decisions when contemplating pregnancy. This review aims to highlight particular issues faced by women with IBD and summarize the current guidance, evidence, and experience available to aid in decision making.

\section{Preconception}

Many women with IBD face challenging decisions when contemplating having children. Active IBD symptoms may negatively impact on body image and libido while anemia and fatigue may reduce the quality of life. ${ }^{4}$ These direct effects of IBD may influence 
women's wishes regarding reproduction regardless of their biological ability to have children. Overall, women with IBD are more likely to be childless than the general population. ${ }^{5}$

Cohort studies have demonstrated that women greatly overestimate the effects of IBD on fertility. ${ }^{3}$ Many fear infertility despite having not tried to conceive and few actively seek medical advice on fertility. ${ }^{3}$ This is also highlighted by the fact that up to $18 \%$ of women with IBD remain voluntarily childless (VC) as compared with only $6 \%$ of the general population. A novel, validated assessment tool of patient knowledge of pregnancy-related issues in IBD found that nearly half of those surveyed had poor knowledge of such issues. ${ }^{6}$ A recent study of 1,324 women has sought to establish the reasons for VC: CCPKnow scores were found to be significantly lower in those patients with IBD who remained $\mathrm{VC}$ as compared to those who contemplated having children (5.98 vs 7.47). ${ }^{7}$

The exact etiology of voluntary childlessness is complex. In a survey of 145 women with IBD, $46 \%$ of participants expressed concerns regarding reduced rates of fertility associated with the condition and $75 \%$ of respondents were concerned regarding the potential for passing their condition to their offspring. ${ }^{8}$ Concerns regarding the effects of disease on a successful pregnancy and the effects of pregnancy on disease course were almost universally held. Furthermore, greater than a third of women included considered all medication used in the treatment of IBD to be harmful in pregnancy. ${ }^{8}$ As such, there is a clear link between poor patient knowledge of IBD- and pregnancy-related issues and views contrary to medical guidance as well as voluntary childlessness.

Current consensus is that there is no significantly increased rate of involuntary childlessness among most IBD populations. ${ }^{1}$ A systematic review of eleven studies into fertility in nonsurgically treated $\mathrm{CD}$ and UC patients found that a perceived $17 \%-44 \%$ reduction in rates of fertility could not be explained by fecundability or fertility issues. ${ }^{9}$ In the case of active $\mathrm{CD}$, fertility is reduced, possibly owing to transmural inflammation or systemic effects of the disease, such as anemia. ${ }^{10-15}$ Rates of fertility are comparable to the general population when clinical remission is achieved and this phenomenon is not noted in UC where fertility mirrors that in non-IBD populations. ${ }^{4,10,16}$

It is however accepted that patients who have undergone surgical procedures related to $\mathrm{CD}$ and $\mathrm{UC}$ are at a greater risk of infertility. ${ }^{16-24}$ The greatest risk would appear to be associated with ileal pouch-anal anastamosis (IPAA) procedures for UC. A meta-analysis of six studies demonstrated a relative risk of infertility after such procedures of 3.91 (95\% confidence interval [CI]: 2.06-7.44) and reported infertility rates varying between $40 \%$ and $80 \%$ depending on the study cohort. ${ }^{25}$ This increased risk is likely secondary to tubal dysfunction related to pelvic adhesions. Laparoscopic approaches for IPAA have become more widely adopted and these seem to be associated with lower infertility rates than those seen with traditional open surgery. ${ }^{26,27}$ While many studies have shown increased rates of physical infertility after surgery (by reporting only patients attempting pregnancy), other factors may also influence the rates of children born after women experienced surgery for IBD. Some women especially those with UC may delay surgery until they have completed their family planning. Indeed, some clinicians advise women with UC who plan to have children to delay pouch surgery after a colectomy until they have had children. On the other hand, surgery may sway women (potentially unnecessarily) toward voluntary childlessness as documented by a recent study. ${ }^{?}$

While the development of IBD has a strong hereditary basis, the condition is not inherited in a Mendelian fashion, with variation in multiple genes contributing modestly to overall risk. Furthermore, many nonhereditary factors are required for IBD to develop. ${ }^{28,29}$ Rates of inheritance vary by type of IBD as parental UC leads to an increased relative risk for the offspring developing CD of 2.6 and UC of 5.1, respectively. ${ }^{30}$ Conversely, parental $\mathrm{CD}$ poses a relative risk for the development of $\mathrm{CD}$ or UC in the offspring of 12.8 and 4.0, respectively. ${ }^{30}$ The absolute risk of a child developing IBD when one parent is affected by either CD or UC is between $4 \%$ and $11 \%$, although this rises to $35 \%$ when conception occurs between two parents suffering from IBD. It is important to note that the fear of passing on IBD to offspring is often in excess of the reported evidence and appropriate reassurance is required for women contemplating motherhood. ${ }^{2}$ Absolute risk may better help patients understand that the risk of offspring developing IBD is actually relatively low.

Preconception counseling in the general population has been persistently shown to promote healthier behaviors and improve pregnancy outcomes. The proven negative effect of misunderstanding fertility- and pregnancy-related issues in IBD has also been shown to be mitigated to some extent by preconception counseling. ${ }^{31}$ Both improved adherence to treatment and reduced relapse rates have been found in IBD patients who received IBD-specific counseling preconception when compared to those who did not. ${ }^{31}$ Furthermore, it has been shown that preconception discussion with a gastroenterologist improves CCPKnow scores, which, as discussed, are associated with reduced odds of voluntary childlessness. ${ }^{32}$ 


\section{Disease behavior during and after pregnancy}

In general, the course of IBD during pregnancy mirrors that of the nonpregnant IBD population and most women will experience a quiescent course of disease during their pregnancies. ${ }^{33-35}$ However, the recent pan-European EPICOM study has suggested increased flare rates for women with UC (relative risk $2.19 ; 95 \%$ CI: $1.25-3.97, P=0.004$ ). ${ }^{36}$

Reports of the disease course in the postpartum period are conflicting. While many women experience reduced disease activity, ${ }^{37,38}$ some studies suggest that women with UC are more likely to experience flares postpartum. ${ }^{36,39}$ Among the theories for a more benign course of IBD during and post-pregnancy, the interplay between maternal and fetal immune systems seems most important. Immuno-tolerance is required to overcome the disparity between maternal and fetal HLA class II antigens. This may in turn alter the intestinal inflammation levels and thereby affect the clinical disease course of IBD. ${ }^{40}$ On the other hand, increased disease activity has been linked to nonadherence to IBD medication in breastfeeding mothers. ${ }^{39}$ Similarly, it is known that adherence to 5-ASA is generally poor in nonpregnant ${ }^{41,42}$ but also in pregnant patients, ${ }^{43}$ which could lead to more flares in women with IBD.

\section{Effects of IBD and IBD disease activity on pregnancy}

IBD can have a profound effect on the course of a pregnancy and pregnancy outcomes. It can, however, be difficult to disentangle what effects stem from having IBD itself (for example, mediated through genes and microbiome), what effects stem from IBD disease activity (mediated through cytokines and the effect of flares on the mother), and what effects are solely related to medication used for the treatment of IBD. Clinicians and patients are faced with complex decisions around medication during pregnancy and breast feeding. This process needs to involve a balancing of the risks associated with a flare of IBD and the risks associated with maintenance medication. To aid this decision making, the implications of any disease flares in the antenatal period need to be understood by both physicians and patients.

While women with quiescent disease can expect normal pregnancy outcomes, this cannot be said for those experiencing active disease during pregnancy. Adverse pregnancy outcomes, including low birth weight, preterm birth, and even fetal loss, have been reported in women with active IBD and especially CD. ${ }^{34,44-47}$ Three recent studies have reported conflicting results: A Danish population-based study confirmed the association of disease activity with preterm birth. ${ }^{48}$ The results of an American population-based study demonstrating no association between disease activity with pre-term birth needs to be treated with caution as the number of patients with active disease was rather small in the study ${ }^{33}$ The latest study from the Netherlands clearly demonstrates that even in the biological treatment age, active disease is associated with worse pregnancy outcomes..$^{49}$ Interestingly, patients with UC experienced more active disease than those with $\mathrm{CD}^{49}$

It remains unclear whether a risk of preterm birth relates to IBD overall or just CD. While a meta-analysis reported a significant risk of preterm births in all IBD patients, ${ }^{33,50}$ this effect disappears for UC when stratifying by disease type. The main association with preterm birth is seen in CD. ${ }^{51,52}$ Consequently, a link between $\mathrm{CD}$ and a lower birth weight has also been found. ${ }^{51,52}$ As such, there is strong evidence to recommend that efforts are made to achieve clinical remission prior to conception and maintain a symptom-free status for the antenatal period. With the exception of mild or quiescent disease, most women will require medication to achieve this. Poorly controlled IBD can have devastating consequences on a pregnancy. The risk of adverse pregnancy outcomes appears to be greatest in those women who have active disease at the time of conception. As such, treatment to avoid and/or treat active disease is vital to ensure a safe and successful pregnancy course.

\section{Congenital abnormalities in offspring of mothers with IBD}

Congenital abnormalities or birth defects can occur in up to $3 \%-7 \%$ of mothers without chronic conditions. As such, they are a worry to any expectant mother, but this also is the case for women with IBD. ${ }^{53}$ Physicians need to know the risks for any congenital abnormalities in offspring to mother with IBD to reassure patients. Unfortunately, due to conflicting evidence, the question over any increased risk of congenital abnormalities in babies to mother with IBD remains difficult to answer.

An American study in Washington showed that maternal UC was associated with an increased risk of malformations $(7.9 \%$ vs $1.7 \% ; P<0.001)$, while no increased risk for CD patients was seen $\left(3.4 \%\right.$; $P=$ not significant).${ }^{51}$ Due to a lack of adjustment for medication use, the study could not provide any insight into effects related to medication rather than disease ${ }^{51}$ Better quality evidence arises from the large Hungarian Case Control Surveillance of Congenital Anomalies (1980-1996) study. The investigators collected comprehensive data and were able to adjust for parity, age, 
and medication use. Importantly, the study reported no overall increase for any malformations (odds ratio [OR]: 1.2, 95\% CI: 0.9-1.8) for UC. ${ }^{54}$ However, when specific types of malformations were examined, a number of significant relationships were found: The risks for limb (OR: 6.2, 95\% CI: 2.9-13.1), urinary tract (OR: 3.3, 95\% CI: 1.1-9.5), and multiple malformations (OR: 2.6, 95\% CI: 1.3-5.4) were significantly increased. ${ }^{54}$ In the overall analysis, however, this effect was offset by lower risks for other abnormalities and the any malformation risk was similar to that in the comparator group.

An Italian case-control study reported a 5.5\% risk of any malformation in offspring to mothers with IBD patients in contrast to a matched control $(0 \%)$ group. ${ }^{52}$ Usually, congenital abnormalities occur in up to $7 \%$ in offspring to healthy mothers. The study has, therefore, a very unusual control rate and the result should be treated with extreme caution due to this bias. ${ }^{53}$

Summary data from a meta-analysis of four studies show the risk of giving birth to offspring with congenital abnormalities was increased for mothers with UC (OR: 2.37, 95\% CI: 1.47-3.82), while for mothers with CD the risk increase did not reach statistical significance (OR: 2.14, 95\% CI: $0.97-4.74 ; P=0.06) .^{50}$

In conclusion, while the data remain difficult to interpret, there seems to be a small increase in congenital malformations in infants born to mothers with UC. Further studies are required to determine the risk for $\mathrm{CD}$ and $\mathrm{IBD}$ overall.

\section{Safety of IBD medication use during pregnancy}

The principle underlying the use of IBD medication during pregnancy is the weighing of risks associated with active disease versus any potential or real risk associated with specific IBD medications. Many patients feel that any medication use could be harmful. ${ }^{8}$ This perception needs to acknowledged and set into context with appropriate counseling with regard to the adverse effects associated with untreated disease. The European Crohn's and Colitis Organisation (ECCO) has recently published the second version of their extensive guidelines on the management of IBD during pregnancy. ${ }^{1}$ The principle underlying medication recommendations in the guidelines is that the risk of active disease usually outweighs any risk from medication (notable exception methotrexate). ${ }^{1}$ Table 1 is an overview of treatment recommendations.

\section{Aminosalicylates}

Aminosalicylates are indicated to treat mild-to-moderate UC. Aminosalicylates are generally considered safe for use in pregnancy as per the ECCO guidelines. ${ }^{1}$

There are a number of studies that have demonstrated the safety of mesalazine use during pregnancy. ${ }^{55}$ There have been no reports that mesalazine increases the risk of congenital abnormalities. ${ }^{56}$ A population-based study that showed an increased incidence of stillbirth and preterm birth in those with Crohn's is likely a result of the underlying disease as opposed to the medication as patients were compared to healthy women. ${ }^{56}$ Asacol was temporarily reclassified by the American Food and Drug Administration as it contained small quantities of phthalates in its coating. Both European and American regulators have suggested removing phthalates from any pharmaceutical agent based on concerns over a potential risk of congenital abnormalities. Asacol preparations for the European and American markets have been changed subsequently and no longer contain phthalates.

Initial reports suggested that sulfasalazine was teratrogenic, ${ }^{57}$ but this has since been refuted. ${ }^{48,58}$ Sulfasalazine does interfere with folate absorption, which is essential for neural tube development. Folic acid supplementation is therefore always required. ${ }^{1}$

Table I ECCO guidance regarding medication use in pregnancy

\begin{tabular}{|c|c|c|}
\hline Drugs & ECCO & Potential risks \\
\hline 5-ASA & Low risk & $\begin{array}{l}\text { Theoretically: stillbirth, preterm birth (confounder in studies: not controlled } \\
\text { for disease activity) }\end{array}$ \\
\hline Thiopurines & Probably low risk & $\begin{array}{l}\text { Low risk of spontaneous miscarriage, preterm labor, and low birth weight } \\
\text { (confounder in studies: not controlled for disease activity) }\end{array}$ \\
\hline Methotrexate & Contraindicated & High risk of fetal mortality and numerous fetal abnormalities \\
\hline Anti-TNF & Probably low risk & $\begin{array}{l}\text { Main risk relates to drug levels in newborn with potential increased risk of } \\
\text { infections; need to avoid live vaccinations }\end{array}$ \\
\hline Prednisolone & Low risk & Low risk of orofacial malformations \\
\hline Anti-integrin & Not included in ECCO guidance & Too few data \\
\hline Anti-IL-23 & Not included in ECCO guidance & Too few data \\
\hline Budesonide & Too few data & Too few data \\
\hline
\end{tabular}

Abbreviations: ECCO, European Crohn's and Colitis Organisation; TNF, tumor necrosis factor; IL-23, interleukin-23. 


\section{Antibiotics}

Antibiotics have a role in the management of both peri-anal $\mathrm{CD}$ and pouchitis. The ECCO guidelines have categorized antibiotics, specifically metronidazole and ciprofloxacin, as low risk for short-term use as there is limited benefit from long-term treatment. ${ }^{1}$

A population-based case control study showed that metronidazole exposure during the second or third trimester was associated with cleft defects. ${ }^{59}$ However, other studies, including a cohort study ${ }^{60}$ with 922 pregnant women and two meta-analysis, ${ }^{61,62}$ have found no increased risk of congenital abnormalities or spontaneous miscarriage relating to metronidazole use.

Quinolones have a high affinity for bone and cartilage and in some animal studies they have been shown to induce arthropathy. ${ }^{63,64}$ However, studies in humans have not shown any increased risk of spontaneous miscarriage or congenital abnormality associated with the use of ciprofloxacin. ${ }^{65}$

\section{Corticosteroids}

Steroids remain the drug of choice for an acute flare of IBD and are recommended for use in the ECCO guidelines. All corticosteroids cross the placenta and some data show adverse effects in humans. Although a number of studies have shown no increased risk of major congenital malformations associated with the use of steroids, there is an increased risk of orofacial malformations if steroids are used in the first trimester. ${ }^{66,67}$ However, not all studies have confirmed these findings, including a large population-based study which included 51,973 pregnancies. $^{68,69}$

There is a single retrospective study looking specifically at the use of budesonide in pregnancy. The study included eight patients who received oral budesonide for $\mathrm{CD}$. The study did not report any adverse pregnancy outcomes associated with its use. ${ }^{70}$ Given its high first-pass metabolism, it is at least in theory unlikely that sufficient quantities of budesonide get transferred across the placenta to exert any pharmacological effect on the fetus.

\section{Thiopurines}

Thiopurines, both azathioprine and 6-mercaptopurine, are indicated for maintenance of remission for both $\mathrm{UC}$ and $\mathrm{CD}$. The ECCO guidelines consider thiopurines to be low risk and well tolerated during pregnancy. ${ }^{1}$

A number of studies have shown adverse outcomes associated with fetal exposure to thiopurines, including increased rate of spontaneous miscarriage, preterm labor, and low birth weight. ${ }^{71,72}$ It is suggested, however, that these outcomes may be a consequence of the underlying IBD rather than due to exposure to thiopurines as exposed patients were compared to a disease-free population.

More recent studies, ${ }^{73-75}$ including a meta-analysis which included 494 patients with IBD, ${ }^{76}$ reported no increased risk for adverse pregnancy outcome in IBD patients treated during pregnancy with thiopurines compared with pregnancy outcomes of IBD patients without this treatment. Interestingly, in a Spanish study, patients on thiopurines had better outcomes than those not exposed to thiopurines, thereby highlighting the importance of disease control throughout pregnancy. ${ }^{75}$

\section{Methotrexate}

Methotrexate is absolutely contraindicated during pregnancy as it is teratogenic. ${ }^{1}$ Methotrexate acts as a folate antagonist and is therefore associated with a high risk of fetal mortality as well as numerous fetal abnormalities. ${ }^{77}$ Current ECCO advice is to stop methotrexate for at least 3-6 months in both men and women before any attempt to conceive is made. ${ }^{1}$

There has been some controversy over the safety of methotrexate in men trying to father a child. While a study of 40 pregnancies with paternal methotrexate exposure found no increased levels of adverse outcomes, ${ }^{78}$ current consensus remains that the potential risk associated with paternal methotrexate should be avoided. ${ }^{1}$

\section{Biologic agents}

In the treatment of IBD, biological agents are used for the treatment of moderate-to-severe $\mathrm{CD}$ and UC. In addition to the antitumor necrosis factor (anti-TNF) class of biologics, which have been widely used for 2 decades, newer biological agents targeting alpha-4-beta-7 integrin and interleukin (IL)-23 have recently entered or about to enter the market.

\section{Anti-TNF agents}

Anti-TNF agents used for IBD include infliximab, adalimumab, golimumab, and in some countries certolizumab. These agents are large molecules, which cannot passively cross the placenta. However, at the end of the second trimester, infliximab and adalimumab are actively transported across the placenta as they resemble maternal immunoglobulins, which are actively transported to help develop the fetal immune system..$^{79}$ As such, fetus is not only exposed to these agents but fetal anti-TNF concentrations often exceed maternal concentrations at birth. ${ }^{80}$ In a recent Australasian study, it took an average of 4 months to achieve full adalimumab clearance and 7 months for full infliximab clearance. ${ }^{80}$ Detectable drug levels were found up to the age of 12 months. ${ }^{80,81}$ It is 
therefore important for safety data to include developmental and infective outcomes in infants in addition to the usual data on pregnancy complications and neonatal outcomes. In contrast to infliximab and adalimumab, certolizumab has a pegylated molecular structure and no placental transfer occurs with either very low or no detectable fetal drug levels at birth. ${ }^{81}$

The ECCO guidelines recommend that anti-TNF agents are probably of low risk during pregnancy. ${ }^{1}$ The safety of infliximab in pregnant women is IBD, which has been assessed by four larger scale studies reporting no significant concerns over maternal or fetal outcomes. ${ }^{81-84}$ Further safety data are emerging from the ongoing "Pregnancy in Inflammatory Bowel Disease and Neonatal Outcomes" (PIANO) study assessing maternal, fetal, developmental, and infective outcomes in the newborn in over 1,000 cases. ${ }^{85}$ These data are only available as conference abstracts at present but suggest that anti-TNF exposure does not lead to developmental problems. ${ }^{85}$ Data on childhood infections remain inconclusive with borderline risk increases. Combination therapy with anti-TNF and thiopurines seems to carry a small increased risk of benign infections in the infant though. ${ }^{80}$ There are fewer data on adalimumab, but these again show no specific safety concern. ${ }^{81,84,86}$ The importance of striking a balance between disease control and drug exposure is highlighted by a Spanish study showing no difference between pregnancy outcomes of mothers with IBD on anti-TNF therapy compared to mothers with IBD neither exposed to biological agents nor thiopurines. ${ }^{75}$ Interestingly, the best outcomes were seen in the group exposed to thiopurines suggesting that the anti-TNF group may had more severe disease but also that the completely unexposed group may have had worse disease control. ${ }^{75}$ The limited data available on certolizumab are reassuring. ${ }^{81,85}$ Data on golimumab exposure are scarce and stem from clinical trials largely, where patients discontinue the drug immediately when pregnancy occurs. ${ }^{87}$

The detectable drug levels in infants to mothers exposed to anti-TNF therapy have implications on the infant's health care. Health care professionals attending the infant should be made aware of the anti-TNF exposure. It would seem sensible to apply lower thresholds for investigations and/or treatment of infective complications where appropriate. The other area of interest is the vaccination program for the new born. At least in theory any live vaccination can pose a risk. There has unfortunately been a death of a 3-month-old child who had been exposed to anti-TNF in utero due to disseminated bacillus Calmette-Guérin (BCG) after receiving the live BCG vaccination. ${ }^{88}$ Based on studies showing detectable drug levels for up to 12 months, it seems prudent to delay any live vaccination until the infant has reached an age of at least 12 months. Rotavirus vaccinations have recently become part of the standard vaccination program in the UK and need to be given before the infant has reached 24 weeks of age. The risk from this live vaccine is unclear, but the PIANO study has reported on a small number of cases with no adverse effects. ${ }^{85}$ For the time being at least, standard advice is, however, to avoid the rotavirus vaccine.

Due to the active placental transfer of biological agents in the third trimester, anti-TNF should be discontinued around 24-26 weeks of gestation if clinical remission has been achieved. ${ }^{1}$ Patients are unlikely to experience a third trimester flare in this setting. ${ }^{89}$ In the case of active disease, however, anti-TNF can safely be continued throughout the third trimester. ${ }^{89}$

\section{Anti-integrin agents}

The alpha-4-beta-7 anti-integrin vedolizumab is a gut-specific agent restricting lymphocyte migration to the gut. It is indicated for moderate-to-severe UC and CD. The currently available limited data stem from the clinical trials program. ${ }^{90}$ While the agent is gut-specific and should have little effect on systemic development, it might in theory have implications for the development of the fetal intestinal immune system. Clinical data are needed urgently to inform clinicians on the safety during pregnancy.

\section{Anti-IL-23 agents}

The blockade of IL-23 has shown good results in patients with $\mathrm{CD}$ and the agent ustekinumab is expected to be licensed for this indication next 12 months. Ustekinumab has been used in the treatment of psoriasis and psoriatic arthritis for a number of years, but safety data for pregnancy are limited with only a handful of case reports. ${ }^{91}$

\section{Medication adherence}

Adherence to IBD medication is often poor outside pregnancy with $30 \%-45 \%$ of patients not taking medication as prescribed. ${ }^{92}$ Given the high concerns expressed by many women with IBD regarding medication during pregnancy ${ }^{2}$ and the extent of views in contrast to medical guidelines, ${ }^{8}$ clinicians must assume that a significant proportion of pregnant women may not adhere to their mediation. While two Danish population-based studies report adherence levels just below of those expected in nonpregnant women, ${ }^{43,93}$ a recent survey reported that $47 \%$ of respondents stopped IBD medication (half on their own accord) when trying to conceive. 


\section{Monitoring of and investigations for IBD during pregnancy Noninvasive monitoring}

Wherever possible, clinical observation and/or noninvasive monitoring is preferred over invasive tests during pregnancy. However, many IBD patients experience physiological changes in their bowel function during pregnancy as expected in healthy women. ${ }^{94} \mathrm{CRP}$ can, however, be influenced by many obstetric conditions ${ }^{95}$ and levels may not reflect IBD activity. Fecal calprotectin may offer a better way of monitoring intestinal inflammation, but the test has not been validated during pregnancy yet and small studies have reported conflicting results regarding its accuracy in the antenatal phase. ${ }^{96,97}$

\section{Imaging during pregnancy}

The decision to proceed to imaging tests needs to incorporate potential harmful effects of radiation and the effects that results of any imaging test may have on treatment decisions. The use of nonionizing radiation imaging is preferred as ultrasound and magnetic resonance imaging are considered safe in pregnancy. ${ }^{98}$ In emergency situations or the absence of a viable alternative, a single exam with ionizing radiation is considered acceptable. ${ }^{98}$

\section{Endoscopy during pregnancy}

Endoscopy can be undertaken during pregnancy provided that it is instrumental for clinical decision making. While ECCO guidance recommends fetal monitoring, ${ }^{99}$ this may not be feasible in many settings. A small Dutch study has shown that maternal and fetal outcomes in patients requiring lower gastrointestinal endoscopy during pregnancy were similar to those not exposed to endoscopy. ${ }^{100} \mathrm{Clinicians}$ should review the need for sedation during endoscopy as this could place an independent, albeit probably very small, risk to the fetus. It is advisable to limit endoscopic examination to the least invasive option offering the required diagnostic value. For example, disease assessment in UC can usually be achieved with a less invasive (and potentially lower risk) sigmoidoscopy rather than a full colonoscopy.

\section{Delivery}

The choice between vaginal delivery and cesarean section is influenced by obstetric and sometimes IBD-related considerations. While women with UC have a cesarean section rate comparable with the general population, women with $\mathrm{CD}$ are more likely to have a cesarean section. ${ }^{50} \mathrm{IBD}$ can influence the choice of delivery method in a number of ways. Preservation of anal sphincter function and maintenance of continence are clearly the long-term aim and fears over negative effects on both may occur in some women. There is also at least in theory a risk of developing de novo perianal disease after a traumatic birth. The rate of this occurring remains unclear. A small Canadian study reported only one case of perianal disease after vaginal delivery and episiotomy in 27 women, ${ }^{101}$ while a self-report survey of 179 women found an $18 \%$ rate postnatal perianal disease. ${ }^{102}$ There was a, however, a high risk of recall and selection bias. ${ }^{102}$

Women with CD without active perianal disease, including those with currently inactive perianal disease, can have a vaginal delivery and episiotomy as they are unlikely to experience postnatal perianal complications. ${ }^{101,103,104}$ When active perianal disease is present during pregnancy, the risk of complications is much higher and cesarean sections should be considered mandatory according to ECCO guidance. ${ }^{105}$ The main concern for women with active perianal disease is that wound healing in an inflamed or even infected perineum will be severely impaired.

In the setting of $U C$, a vaginal delivery is usually advised with the notable exception for women with previous IPAA surgery. ${ }^{105}$ While it has been established that vaginal delivery is associated with pathophysiological changes in anal sphincter function, it remains unclear whether this leads to problems with long-term pouch function. ${ }^{20,22,106}$ Anorectal physiology is often impaired (lower squeeze pressure) and anorectal sonography shows more anal sphincter defects, but this was not associated with differences in clinical outcomes. ${ }^{107} \mathrm{~A}$ large study of 232 women who gave birth after IPAA surgery found, however, no differences in functional outcomes. ${ }^{108}$ This finding is further supported by a survey comparing 85 women with vaginal deliveries after IPAA to 343 age-matched women who did not have children after IPAA. ${ }^{109}$ No differences in outcomes were found similar to a smaller Finnish study of 39 women. ${ }^{110}$

ECCO guidance, however, suggests that cesarean section may be preferable after IPAA surgery as women are likely to have borderline continence in the first instance. ${ }^{105}$

\section{Breast feeding}

During pregnancy, women with IBD face the dilemma of weighing the risk of flares against the risks of medication without the option of avoiding these risks completely. The choice between breast feeding and bottle feeding allows, however, the chance to avoid any drug exposure in the newborn completely. As breast feeding has several advantages over bottle feeding, the mother with IBD is forced to make a choice 
between the potential benefits of breast feeding versus the risk of exposure to small amounts of drug.

A number of health benefits derive from breast milk, including the provision of complete, tailored nutrition and maternal immunoglobulins. These help to develop the infant's immune system. ${ }^{111}$ Breast milk may also provide protective effects in reducing the incidence of atopic diseases and even IBD, but most studies are of low quality with recall bias and lack of standardization of duration of breast feeding. ${ }^{112}$ A meta-analysis of 17 studies showed that breast feeding reduced the risk of IBD developing in offspring to healthy mothers (OR: 0.67 [95\% CI: 0.52-0.86] for CD and OR: 0.77 [95\% CI: 0.61-0.96] for UC). It is, however, unclear whether breast feeding has any protective effect in offspring to mothers with IBD, where genetic factors may play a greater role in the development of IBD.

Breastfeeding rates in women with IBD are lower than expected, ${ }^{39}$ which may be explained by fears over medication effects. In a recent study, $56 \%$ of women believed that all IBD medication would be a barrier to breast feeding. ${ }^{8}$

While small quantities of IBD medication can often be detected in breast milk, this does not necessarily exert any biological effects on the infant. Table 2 contains the ECCO guidance on IBD medication and breast feeding. Based on only two cases of bloody diarrhea, the American Academy of Pediatrics classed aminosalicylates as a contraindication to breast feeding. ${ }^{113-115}$ ECCO guidance judges aminosalicylates as low risk in view of low drug levels in breast milk and infants' blood. ${ }^{1,116-118}$

For women with corticosteroid exposure, ECCO guidance suggests leaving a 4-hour gap between medication and feeding to reduce drug levels. ${ }^{1,105,119}$ Thiopurine metabolites (ECCO: low risk) are often undetectable or found in extremely low quantities in breast milk ${ }^{120-122}$ and are usually not detectable in infants. ${ }^{123,124}$

Adalimumab and infliximab can be detected in breast milk in very small concentrations, ${ }^{125,126}$ but usually require parenteral rather than enteral administration to exert an effect (ECCO: probably risk ${ }^{1}$ ). Methotrexate is again considered contraindicated. ${ }^{1}$

Table 2 ECCO guidance on medication use while breast feeding

\begin{tabular}{ll}
\hline Medication & ECCO guidance \\
\hline Mesalazine/sulfasalazine & Low risk \\
Corticosteroids & Low risk \\
Thiopurines & Low risk \\
Anti-TNF & Probably low risk \\
Methotrexate & Contraindicated \\
\hline
\end{tabular}

Abbreviations: ECCO, European Crohn's and Colitis Organisation; TNF, tumor necrosis factor.

\section{Conclusion}

Women with IBD face complex decisions when contemplating having children and many remain childless. To help them achieve their life ambitions, these patients should be supported by appropriate prepregnancy counseling, and antenatal IBD care focused on maintaining remission, specialist obstetric input, and a pregnancy plan that includes advice on delivery methods and breast feeding.

\section{Author contributions}

MP and KL reviewed the literature and wrote the draft manuscript. CPS reviewed the literature and critically reviewed the manuscript.

\section{Disclosure}

CPS has received unrestricted research grants from Warner Chilcott and AbbVie; has provided consultancy to Warner Chilcott, Dr Falk, AbbVie, and Takeda; and had speaker arrangements with Warner Chilcott, Dr Falk, AbbVie, MSD, and Takeda. The other authors report no conflict of interest in this work.

\section{References}

1. van der Woude CJ, Ardizzone S, Bengtson MB, et al. The second European evidenced-based consensus on reproduction and pregnancy in inflammatory bowel disease. J Crohns Colitis. 2015;9(2):107-124.

2. Mountifield RE, Prosser R, Bampton P, Muller K, Andrews JM. Pregnancy and IBD treatment: this challenging interplay from a patients' perspective. J Crohns Colitis. 2010;4(2):176-182.

3. Mountifield R, Bampton P, Prosser R, Muller K, Andrews JM. Fear and fertility in inflammatory bowel disease: a mismatch of perception and reality affects family planning decisions. Inflamm Bowel Dis. 2009;15(5):720-725.

4. Dubinsky M, Abraham B, Mahadevan U. Management of the pregnant IBD patient. Inflamm Bowel Dis. 2008;14(12):1736-1750.

5. Marri SR, Ahn C, Buchman AL. Voluntary childlessness is increased in women with inflammatory bowel disease. Inflamm Bowel Dis. 2007;13(5):591-599.

6. Selinger CP, Eaden J, Selby W, et al. Patients' knowledge of pregnancy-related issues in inflammatory bowel disease and validation of a novel assessment tool ('CCPKnow'). Aliment Pharmacol Ther. 2012;36(1):57-63.

7. Selinger CP, Ghorayeb J, Madill A. What Factors Might Drive Voluntary Childlessness (VC) in Women with IBD? Does IBD-specific Pregnancyrelated Knowledge Matter? J Crohns Colitis. Epub 2016 Mar 17.

8. Selinger CP, Eaden J, Selby W, et al. Inflammatory bowel disease and pregnancy: Lack of knowledge is associated with negative views. $J$ Crohns Colitis. 2012;7(6):e206-e213.

9. Tavernier N, Fumery M, Peyrin-Biroulet L, Colombel JF, Gower-Rousseau C. Systematic review: fertility in non-surgically treated inflammatory bowel disease. Aliment Pharmacol Ther. 2013;38(8):847-853.

10. Baird DD, Narendranathan M, Sandler RS. Increased risk of preterm birth for women with inflammatory bowel disease. Gastroenterology. 1990;99(4):987-994.

11. Khosla R, Willoughby CP, Jewell DP. Crohn's disease and pregnancy. Gut. 1984;25(1):52-56.

12. Woolfson K, Cohen Z, McLeod RS. Crohn's disease and pregnancy. Dis Colon Rectum. 1990;33(10):869-873. 
13. Fonager K, Sørensen HT, Olsen J, Dahlerup JF, Rasmussen SN. Pregnancy outcome for women with Crohn's disease: a follow-up study based on linkage between national registries. Am J Gastroenterol. 1998;93(12):2426-2430.

14. Baiocco PJ, Korelitz BI. The influence of inflammatory bowel disease and its treatment on pregnancy and fetal outcome. J Clin Gastroenterol. 1984;6(3):211-216.

15. Mayberry JF, Weterman IT. European survey of fertility and pregnancy in women with Crohn's disease: a case control study by European collaborative group. Gut. 1986;27(7):821-825.

16. Hudson M, Flett G, Sinclair TS, Brunt PW, Templeton A, Mowat NA. Fertility and pregnancy in inflammatory bowel disease. Int J Gynaecol Obstet. 1997;58(2):229-237.

17. Olsen KO, Joelsson M, Laurberg S, Oresland T. Fertility after ileal pouch-anal anastomosis in women with ulcerative colitis. Br J Surg. 1999;86(4):493-495

18. Ørding Olsen K, Juul S, Berndtsson I, Oresland T, Laurberg S. Ulcerative colitis: female fecundity before diagnosis, during disease, and after surgery compared with a population sample. Gastroenterology. 2002;122(1):15-19.

19. Oresland T, Palmblad S, Ellström M, Berndtsson I, Crona N, Hultén L. Gynaecological and sexual function related to anatomical changes in the female pelvis after restorative proctocolectomy. Int J Colorectal Dis. 1994;9(2):77-81.

20. Ravid A, Richard CS, Spencer LM, et al. Pregnancy, delivery, and pouch function after ileal pouch-anal anastomosis for ulcerative colitis. Dis Colon Rectum. 2002;45(10):1283-1288.

21. Tiainen J, Matikainen M, Hiltunen KM. Ileal J-pouch - anal anastomosis, sexual dysfunction, and fertility. Scand J Gastroenterol. 1999;34(2):185-188

22. Juhasz ES, Fozard B, Dozois RR, Ilstrup DM, Nelson H. Ileal pouch-anal anastomosis function following childbirth. An extended evaluation. Dis Colon Rectum. 1995;38(2):159-165.

23. Damgaard B, Wettergren A, Kirkegaard P. Social and sexual function following ileal pouch-anal anastomosis. Dis Colon Rectum. 1995;38(3):286-289.

24. Johnson E, Carlsen E, Nazir M, Nygaard K. Morbidity and functional outcome after restorative proctocolectomy for ulcerative colitis. Eur J Surg. 2001;167(1):40-45.

25. Rajaratnam SG, Eglinton TW, Hider P, Fearnhead NS. Impact of ileal pouch-anal anastomosis on female fertility: meta-analysis and systematic review. Int J Colorectal Dis. 2011;26(11):1365-1374.

26. Beyer-Berjot L, Maggiori L, Birnbaum D, Lefevre JH, Berdah S, Panis Y A total laparoscopic approach reduces the infertility rate after ileal pouch-anal anastomosis: a 2-center study. Ann Surg. 2013;258(2): 275-282.

27. Bartels SA, D’Hoore A, Cuesta MA, Bensdorp AJ, Lucas C, Bemelman WA. Significantly increased pregnancy rates after laparoscopic restorative proctocolectomy: a cross-sectional study. Ann Surg. 2012;256(6):1045-1048.

28. Orholm M, Binder V, Sørensen TI, Rasmussen LP, Kyvik KO. Concordance of inflammatory bowel disease among Danish twins. Results of a nationwide study. Scand J Gastroenterol. 2000;35(10):1075-1081.

29. Tysk C, Lindberg E, Järnerot G, Flodérus-Myrhed B. Ulcerative colitis and Crohn's disease in an unselected population of monozygotic and dizygotic twins. A study of heritability and the influence of smoking. Gut. 1988;29(7):990-996.

30. Peeters M, Nevens H, Baert F, Hiele M, de Meyer AM, Vlietinck R, Rutgeerts P. Familial aggregation in Crohn's disease: increased ageadjusted risk and concordance in clinical characteristics. Gastroenterology. 1996;111(3):597-603.

31. de Lima A, Zelinkova Z, Mulders AG, van der Woude CJ. Preconception care reduces relapse of inflammatory bowel disease during pregnancy. Clin Gastroenterol Hepatol. 2016;14(9):1285e1-1292e1.

32. Carbery I, Ghorayeb J, Madill A, Selinger CP. Pregnancy and inflammatory bowel disease: do we provide enough patient education? A British study of 1324 women. World J Gastroenterol. 2016;22(36):8219-8225.
33. Mahadevan U, Sandborn WJ, Li DK, Hakimian S, Kane S, Corley DA. Pregnancy outcomes in women with inflammatory bowel disease: a large community-based study from Northern California. Gastroenterology. 2007;133(4):1106-1112.

34. Nielsen OH, Andreasson B, Bondesen S, Jarnum S. Pregnancy in ulcerative colitis. Scand J Gastroenterol. 1983;18(6):735-742.

35. Nielsen $\mathrm{OH}$, Andreasson B, Bondesen S, Jacobsen O, Jarnum S. Pregnancy in Crohn's disease. Scand J Gastroenterol. 1984;19(6): 724-732.

36. Pedersen N, Bortoli A, Duricova D, et al. The course of inflammatory bowel disease during pregnancy and postpartum: a prospective European ECCO-EpiCom Study of 209 pregnant women. Aliment Pharmacol Ther. 2013;38(5):501-512.

37. Castiglione F, Pignata S, Morace F, et al. Effect of pregnancy on the clinical course of a cohort of women with inflammatory bowel disease. Ital J Gastroenterol. 1996;28(4):199-204.

38. Riis L, Vind I, Politi P, et al. Does pregnancy change the disease course? A study in a European cohort of patients with inflammatory bowel disease. Am J Gastroenterol. 2006;101(7):1539-1545.

39. Kane S, Lemieux N. The role of breastfeeding in postpartum disease activity in women with inflammatory bowel disease. Am J Gastroenterol. 2005;100(1):102-105.

40. Kane S, Kisiel J, Shih L, Hanauer S. HLA disparity determines disease activity through pregnancy in women with inflammatory bowel disease. Am J Gastroenterol. 2004;99(8):1523-1526.

41. Selinger C, Eaden J, Jones B, et al. Modifiable factors associated with nonadherence to maintenance medication for inflammatory bowel disease. Inflamm Bowel Dis. 2013;19(10):2199-2206.

42. Selinger CP, Kemp A, Leong RW. Persistence to oral 5-aminosalicylate therapy for inflammatory bowel disease in Australia. Expert Rev Gastroenterol Hepatol. 2014;8(3):329-334.

43. Julsgaard M, Nørgaard M, Hvas CL, Buck D, Christensen LA. Self-reported adherence to medical treatment prior to and during pregnancy among women with ulcerative colitis. Inflamm Bowel Dis. 2010;17(7):1573-1580.

44. Morales M, Berney T, Jenny A, Morel P, Extermann P. Crohn's disease as a risk factor for the outcome of pregnancy. Hepatogastroenterology. 2000;47(36):1595-1598.

45. Bush MC, Patel S, Lapinski RH, Stone JL. Perinatal outcomes in inflammatory bowel disease. J Matern Fetal Neonatal Med. 2004;15(4):237-241.

46. Fedorkow DM, Persaud D, Nimrod CA. Inflammatory bowel disease: a controlled study of late pregnancy outcome. Am J Obstet Gynecol. 1989;160(4):998-1001.

47. Abdul Sultan A, West J, Ban L, et al. Adverse pregnancy outcomes among women with inflammatory bowel disease: a population-based study from England. Inflamm Bowel Dis. 2016;22(7):1621-1630.

48. Nørgård B, Hundborg HH, Jacobsen BA, Nielsen GL, Fonager K. Disease activity in pregnant women with Crohn's disease and birth outcomes: a regional Danish cohort study. Am J Gastroenterol. 2007;102(9):1947-1954.

49. de Lima-Karagiannis A, Zelinkova-Detkova Z, van der Woude CJ. The effects of active IBD during pregnancy in the era of novel IBD therapies. Am J Gastroenterol. 2016;111(9):1305-1312.

50. Cornish J, Tan E, Teare J, Teoh TG, Rai R, Clark SK, Tekkis PP. A metaanalysis on the influence of inflammatory bowel disease on pregnancy. Gut. 2007;56(6):830-837.

51. Dominitz JA, Young JC, Boyko EJ. Outcomes of infants born to mothers with inflammatory bowel disease: a population-based cohort study. $\mathrm{Am}$ J Gastroenterol. 2002;97(3):641-648.

52. Bortoli A, Saibeni S, Tatarella M, et al. Pregnancy before and after the diagnosis of inflammatory bowel diseases: retrospective case-control study. J Gastroenterol Hepatol. 2007;22(4):542-549.

53. Arbour LT, Beking K, Le ND, et al. Rates of congenital anomalies and other adverse birth outcomes in an offspring cohort of registered nurses from British Columbia, Canada. Can J Public Health. 2010;101(3):230-234. 
54. Nørgård B, Puho E, Pedersen L, Czeizel AE, Sørensen HT. Risk of congenital abnormalities in children born to women with ulcerative colitis: a population-based, case-control study. Am J Gastroenterol. 2003;98(9):2006-2010.

55. Rahimi R, Nikfar S, Rezaie A, Abdollahi M. Pregnancy outcome in women with inflammatory bowel disease following exposure to 5-aminosalicylic acid drugs: a meta-analysis. Reprod Toxicol. 2008;25(2):271-275.

56. Nørgård B, Fonager K, Pedersen L, Jacobsen BA, Sørensen HT. Birth outcome in women exposed to 5-aminosalicylic acid during pregnancy: a Danish cohort study. Gut. 2003;52(2):243-247.

57. Newman NM, Correy JF. Possible teratogenicity of sulphasalazine. Med J Aust. 1983;1(11):528-529.

58. Mogadam M, Dobbins WO, Korelitz BI, Ahmed SW. Pregnancy in inflammatory bowel disease: effect of sulfasalazine and corticosteroids on fetal outcome. Gastroenterology. 1981;80(1):72-76.

59. Czeizel AE, Rockenbauer M. A population based case-control teratologic study of oral metronidazole treatment during pregnancy. $\mathrm{Br} \mathrm{J}$ Obstet Gynaecol. 1998;105(3):322-327.

60. Koss CA, Baras DC, Lane SD, Aubry R, Marcus M, Markowitz $\mathrm{LE}$, Koumans EH. Investigation of metronidazole use during pregnancy and adverse birth outcomes. Antimicrob Agents Chemother. 2012;56(9):4800-4805.

61. Caro-Patón T, Carvajal A, Martin de Diego I, Martin-Arias LH, Alvarez Requejo A, Rodríguez Pinilla E. Is metronidazole teratogenic? A metaanalysis. Br J Clin Pharmacol. 1997;44(2):179-182.

62. Burtin P, Taddio A, Ariburnu O, Einarson TR, Koren G. Safety of metronidazole in pregnancy: a meta-analysis. Am J Obstet Gynecol. 1995;172(2 Pt 1):525-529.

63. Linseman DA, Hampton LA, Branstetter DG. Quinolone-induced arthropathy in the neonatal mouse. Morphological analysis of articular lesions produced by pipemidic acid and ciprofloxacin. Fundam Appl Toxicol. 1995;28(1):59-64.

64. Niebyl JR. Antibiotics and other anti-infective agents in pregnancy and lactation. Am J Perinatol. 2003;20(8):405-414.

65. Bar-Oz B, Moretti ME, Boskovic R, O’Brien L, Koren G. The safety of quinolones--a meta-analysis of pregnancy outcomes. Eur J Obstet Gynecol Reprod Biol. 2009;143(2):75-78.

66. Park-Wyllie L, Mazzotta P, Pastuszak A, et al. Birth defects after maternal exposure to corticosteroids: prospective cohort study and metaanalysis of epidemiological studies. Teratology. 2000;62(6):385-392.

67. Carmichael SL, Shaw GM, Ma C, et al. Maternal corticosteroid use and orofacial clefts. Am J Obstet Gynecol. 2007;197(6):585e1-587e1. discussion 683-584, e581-e587.

68. Gur C, Diav-Citrin O, Shechtman S, Arnon J, Ornoy A. Pregnancy outcome after first trimester exposure to corticosteroids: a prospective controlled study. Reprod Toxicol. 2004;18(1):93-101.

69. Hviid A, Molgaard-Nielsen D. Corticosteroid use during pregnancy and risk of orofacial clefts. CMAJ. 2011;183(7):796-804.

70. Beaulieu DB, Ananthakrishnan AN, Issa M, et al. Budesonide induction and maintenance therapy for Crohn's disease during pregnancy. Inflamm Bowel Dis. 2009;15(1):25-28.

71. Cleary BJ, Kallen B. Early pregnancy azathioprine use and pregnancy outcomes. Birth Defects Res A Clin Mol Teratol. 2009;85(7):647-654.

72. Nørgård B, Pedersen L, Fonager K, Rasmussen SN, Sørensen HT. Azathioprine, mercaptopurine and birth outcome: a population-based cohort study. Aliment Pharmacol Ther. 2003;17(6):827-834.

73. Francella A, Dyan A, Bodian C, Rubin P, Chapman M, Present DH. The safety of 6-mercaptopurine for childbearing patients with inflammatory bowel disease: a retrospective cohort study. Gastroenterology. 2003;124(1):9-17.

74. Moskovitz DN, Bodian C, Chapman ML, Marion JF, Rubin PH, Scherl E, Present DH. The effect on the fetus of medications used to treat pregnant inflammatory bowel-disease patients. Am J Gastroenterol. 2004;99(4):656-661.

75. Casanova MJ, Chaparro M, Domènech E, et al. Safety of thiopurines and anti-TNF- $\alpha$ drugs during pregnancy in patients with inflammatory bowel disease. Am J Gastroenterol. 2013;108(3):433-440.
76. Hutson JR, Matlow JN, Moretti ME, Koren G. The fetal safety of thiopurines for the treatment of inflammatory bowel disease in pregnancy. J Obstet Gynaecol. 2013;33(1):1-8.

77. Connell WR. Safety of drug therapy for inflammatory bowel disease in pregnant and nursing women. Inflamm Bowel Dis. 1996;2(1):33-47.

78. Beghin D, Cournot MP, Vauzelle C, Elefant E. Paternal exposure to methotrexate and pregnancy outcomes. J Rheumatol. 2011;38(4):628-632.

79. Simister NE. Placental transport of immunoglobulin G. Vaccine. 2003;21(24):3365-3369.

80. Julsgaard M, Christensen LA, Gibson PR, et al. Concentrations of adalimumab and infliximab in mothers and newborns, and effects on infection. Gastroenterology. 2016;151(1):110-119.

81. Mahadevan U, Wolf DC, Dubinsky M, et al. Placental transfer of antitumor necrosis factor agents in pregnant patients with inflammatory bowel disease. Clin Gastroenterol Hepatol. 2013;11(3):286-292; quiz e224.

82. Lichtenstein GR, Feagan BG, Cohen RD, et al. Serious infections and mortality in association with therapies for Crohn's disease: TREAT registry. Clin Gastroenterol Hepatol. 2006;4(5):621-630.

83. Katz JA, Antoni C, Keenan GF, Smith DE, Jacobs SJ, Lichtenstein GR. Outcome of pregnancy in women receiving infliximab for the treatment of Crohn's disease and rheumatoid arthritis. Am J Gastroenterol. 2004;99(12):2385-2392.

84. Schnitzler F, Fidder H, Ferrante M, et al. Outcome of pregnancy in women with inflammatory bowel disease treated with antitumor necrosis factor therapy. Inflamm Bowel Dis. 2011;17(9):1846-1854.

85. Mahadevan U, Martin C, Sandler R. A 1000 patient prospective registry of pregnancy outcomes in women with IBD exposed to immunomodulators and biologic therapy [abstract 865]. Gastroenterology. 2012;142(5 suppl 1):S-149.

86. Zelinkova Z, van der Ent C, Bruin KF, et al. Effects of discontinuing anti-tumor necrosis factor therapy during pregnancy on the course of inflammatory bowel disease and neonatal exposure. Clin Gastroenterol Hepatol. 2013;11(3):318-321.

87. Lau A, Cleark M, Harriosn D, Geldhof A, Nissinen R, Sanders M. Pregnancy outcomes in women exposed to golimumab. Presented at: ACR/ARHP Annual Meeting; 2013; San Diego, CA, USA.

88. Cheent K, Nolan J, Shariq S, Kiho L, Pal A, Arnold J. Case report: fatal case of disseminated BCG infection in an infant born to a mother taking infliximab for Crohn's disease. J Crohns Colitis. 2010;4(5):603-605.

89. de Lima A, Zelinkova Z, van der Ent C, Steegers EA, van der Woude CJ. Tailored anti-TNF therapy during pregnancy in patients with IBD: maternal and fetal safety. Gut. 2016;65(8):1261-1268.

90. Dubinsky M, Mahadevan U, Vermeire S, Abhyankar B, Lasch K. Vedolizumab exposure in pregnancy: outcomes from clinical studies in inflammatory bowel disease. Poster presented at: Clinical: Therapy \& Observation; European Crohns and Colitis Organisation; 2015; Barcelona.

91. Rocha K, Piccinin MC, Kalache LF, Reichert-Faria A, Silva de Castro CC. Pregnancy during Ustekinumab Treatment for Severe Psoriasis. Dermatology. 2015;231(2):103-104.

92. Selinger CP, Robinson A, Leong RW. Clinical impact and drivers of non-adherence to maintenance medication for inflammatory bowel disease. Expert Opin Drug Saf. 2011;10(6):863-870.

93. Nielsen MJ, Nørgaard M, Holland-Fisher P, Christensen LA. Self-reported antenatal adherence to medical treatment among pregnant women with Crohn's disease. Aliment Pharmacol Ther. 2010;32(1):49-58.

94. Derbyshire EJ, Davies J, Detmar P. Changes in bowel function: pregnancy and the puerperium. Dig Dis Sci. 2007;52(2):324-328.

95. Shahshahan Z, Iravani H. Comparison of CRP and ALK-P serum levels in prediction of preterm delivery. Adv Biomed Res. 2016;5:17.

96. Huang V, Bal J, Foshaug R, et al. Fecal calprotectin is elevated with clinical disease activity during pregnancy in women with inflammatory bowel disease. Poster presented at: Clinical: Therapy \& Observation (2015); European Crohns and Colitis Organisation; 2015; Barcelona.

97. Shitrit A, Granovsky- Grisaru S, Adar T, Koslowsky B, Livovsky DM, Shteingart S, Goldin E. Limitations in using fecal Calprotectin as a biomarker of IBD disease activity during pregnancy. Poster presented at: Clinical: Therapy \& Observation (2015); European Crohns and Colitis Organisation; 2015; Barcelona. 
98. Committee Opinion. Guidelines for Diagnostic Imaging during Pregnancy. American Washington, DC, USA: College of Obstetricians and Gynecologists; 2004.

99. van der Woude CJ, Kolacek S, Dotan I, et al. European evidenced-based consensus on reproduction in inflammatory bowel disease. J Crohns Colitis. 2010;4(5):493-510.

100. de Lima A, Zelinkova Z, van der Woude CJ. A prospective study of the safety of lower gastrointestinal endoscopy during pregnancy in patients with inflammatory bowel disease. J Crohns Colitis. 2015;9(7):519-524.

101. Ilnyckyji A, Blanchard JF, Rawsthorne P, Bernstein CN. Perianal Crohn's disease and pregnancy: role of the mode of delivery. Am J Gastroenterol. 1999;94(11):3274-3278.

102. Brandt LJ, Estabrook SG, Reinus JF. Results of a survey to evaluate whether vaginal delivery and episiotomy lead to perineal involvement in women with Crohn's disease. Am J Gastroenterol. 1995;90(11):1918-1922.

103. Beniada A, Benoist G, Maurel J, Dreyfus M. [Inflammatory bowel disease and pregnancy: report of 76 cases and review of the literature]. J Gynecol Obstet Biol Reprod (Paris). 2005;34(6):581-588. French.

104. Rogers RG, Katz VL. Course of Crohn's disease during pregnancy and its effect on pregnancy outcome: a retrospective review. Am J Perinatol. 1995;12(4):262-264.

105. Van Assche G, Dignass A, Reinisch W, et al. The second European evidence-based consensus on the diagnosis and management of Crohn's disease: Special situations. J Crohns Colitis. 2010;4(1):63-101.

106. Kitayama T, Funayama Y, Fukushima K, et al. Anal function during pregnancy and postpartum after ileal pouch anal anastomosis for ulcerative colitis. Surg Today. 2005;35(3):211-215.

107. Remzi FH, Gorgun E, Bast J, et al. Vaginal delivery after ileal pouchanal anastomosis: a word of caution. Dis Colon Rectum. 2005;48(9): 1691-1699.

108. Hahnloser D, Pemberton JH, Wolff BG, Larson D, Harrington J, Farouk R, Dozois RR. Pregnancy and delivery before and after ileal pouch-anal anastomosis for inflammatory bowel disease: immediate and long-term consequences and outcomes. Dis Colon Rectum. 2004;47(7):1127-1135

109. Farouk R, Pemberton JH, Wolff BG, Dozois RR, Browning S, Larson D. Functional outcomes after ileal pouch-anal anastomosis for chronic ulcerative colitis. Ann Surg. 2000;231(6):919-926.

110. Lepistö A, Sarna S, Tiitinen A, Järvinen HJ. Female fertility and childbirth after ileal pouch-anal anastomosis for ulcerative colitis. $\mathrm{Br}$ J Surg. 2007;94(4):478-482.
111. Jackson KM, Nazar AM. Breastfeeding, the immune response, and long-term health. J Am Osteopath Assoc. 2006;106(4):203-207.

112. Klement E, Cohen RV, Boxman J, Joseph A, Reif S. Breastfeeding and risk of inflammatory bowel disease: a systematic review with meta-analysis. Am J Clin Nutr. 2004;80(5):1342-1352.

113. Branski D, Kerem E, Gross-Kieselstein E, Hurvitz H, Litt R, Abrahamov A. Bloody diarrhea - a possible complication of sulfasalazine transferred through human breast milk. J Pediatr Gastroenterol Nutr. 1986;5(2):316-317.

114. Nelis GF. Diarrhoea due to 5-aminosalicylic acid in breast milk. Lancet 1989;1(8634):383.

115. Drugs AAoPCo. Transfer of drugs and other chemicals into human milk. Pediatrics. 2001;108(3):776-789.

116. Habal FM, Hui G, Greenberg GR. Oral 5-aminosalicylic acid for inflammatory bowel disease in pregnancy: safety and clinical course. Gastroenterology. 1993;105(4):1057-1060.

117. Esbjörner E, Järnerot G, Wranne L. Sulphasalazine and sulphapyridine serum levels in children to mothers treated with sulphasalazine during pregnancy and lactation. Acta Paediatr Scand. 1987;76(1): 137-142.

118. Silverman DA, Ford J, Shaw I, Probert CS. Is mesalazine really safe for use in breastfeeding mothers? Gut. 2005;54(1):170-171.

119. Ost L, Wettrell G, Björkhem I, Rane A. Prednisolone excretion in human milk. J Pediatr. 1985;106(6):1008-1011.

120. Coulam CB, Moyer TP, Jiang NS, Zincke H. Breast-feeding after renal transplantation. Transplant Proc. 1982;14(3):605-609.

121. Christensen LA, Dahlerup JF, Nielsen MJ, Fallingborg JF, Schmiegelow K. Azathioprine treatment during lactation. Aliment Pharmacol Ther. 2008;28(10):1209-1213.

122. Moretti ME, Verjee Z, Ito S, Koren G. Breast-feeding during maternal use of azathioprine. Ann Pharmacother. 2006;40(12):2269-2272.

123. Gardiner SJ, Gearry RB, Roberts RL, Zhang M, Barclay ML, Begg EJ. Exposure to thiopurine drugs through breast milk is low based on metabolite concentrations in mother-infant pairs. Br J Clin Pharmacol. 2006;62(4):453-456.

124. Sau A, Clarke S, Bass J, Kaiser A, Marinaki A, Nelson-Piercy C. Azathioprine and breastfeeding: is it safe? BJOG. 2007;114(4):498-501.

125. Ben-Horin S, Yavzori M, Katz L, et al. Adalimumab level in breast milk of a nursing mother. Clin Gastroenterol Hepatol. 2010;8(5): 475-476.

126. Ben-Horin S, Yavzori M, Kopylov U, et al. Detection of infliximab in breast milk of nursing mothers with inflammatory bowel disease. J Crohns Colitis. 2011;5(6):555-558.

\section{Clinical and Experimental Gastroenterology}

\section{Publish your work in this journal}

Clinical and Experimental Gastroenterology is an international, peerreviewed, open access, online journal publishing original research, reports, editorials, reviews and commentaries on all aspects of gastroenterology in the clinic and laboratory. This journal is included on PubMed. The manuscript management system is completely online

\section{Dovepress}

and includes a very quick and fair peer-review system, which is all easy to use. Visit http://www.dovepress.com/testimonials.php to read real quotes from published authors. 